\title{
NORMAL HEAD GROWTH AND THE PREDICTION OF HEAD SIZE IN INFANTILE HYDROCEPHALUS
}

\author{
BY \\ EILEEN M. O'NEILL \\ From the Department of Paediatrics, City General Hospital, Sheffield
}

(RECEIVED FOR PUBLICATION OCTOBER 24, 1960)

\section{PART I}

Normal Standards of Head Size and Growth in Full-term and Premature Babies

The earliest possible detection of progressive infantile hydrocephalus requires more detailed standards of normal head size and growth than any previously published. The first part of this communication has been prepared with the object of providing such standards for both full-term and premature babies.

There are two distinct ways of collecting growth data. When values are obtained from different children at different ages, no child having been measured more than once, the study is said to be cross-sectional and the values obtained from it provide only distance standards. This means that they can be used only for assessing size achieved by a certain age. If increments of growth (velocity standards) are required they should, according to Tanner (1952), be obtained from longitudinal (or serial) studies in which the same children are followed up and measured at different ages. In fact most growth studies are not purely of one type or the other.

With regard to head size in newborn babies, distance standards available in this country are inadequate in that in none of the published series is head size related to birth weight, whereas the range of normal head circumference for a small infant is quite different from that of a larger one. After the first few days of life actual head size is overshadowed by the far more important rate of head growth, normals for which we have already seen must be obtained from longitudinal studies. Before 1952, all surveys of infantile head size on British children were of the cross-sectional type, an example of which is that of Myers (1926) in which measurements were taken from 1,400 London children.
Since 1952, results of three longitudinal surveys of head growth of British children have been published (Low, 1952; Westropp and Barber, 1956; Falkner, 1958) and all, therefore, are suitable for calculating normal velocity standards. Low (1952) recorded head circumference values at 3 days of age and then at yearly intervals. Westropp and Barber (1956) made more frequent measurements on the 331 boys and 333 girls of their series. The heads of these children were measured at 1 month, 3 months, 6 months, 9 months and 1 year, and thereafter at half-yearly intervals up to 7 years. In Falkner's (1958) survey the data were obtained at $4,13,26,39$ and 52 weeks of age and then at less frequent intervals up to 3 years. These studies, however, are inadequate for the early detection of abnormal rates of head growth because the units of time for which the increments of growth can be or have been calculated are so great that, if they are used, the diagnosis of progressive hydrocephalus must be very much delayed.

No mention has so far been made of the normal head circumference values of premature babies, and the only references to such measurements in the literature are those of Crosse (1957) and Anderson (1950). Only in the latter was the range of normal given and both were almost certainly from crosssectional data.

To summarize, then, it was felt that there was a definite need for detailed longitudinal studies of head growth in both full-term and premature babies. Such a survey was embarked upon with the object of obtaining data suitable for assessing the head size of all babies at birth and rates of head growth at intervals of one or two weeks, as only by these means could treatment for progressive hydrocephalus be instituted early enough to be successful.

\section{Material}

The babies included in this survey were white children born either in the Maternity Unit of the City General 
Hospital, Sheffield, or St. Helen Hospital, Barnsley. A small minority was born at home and admitted shortly after birth because of low birth weight. The infants chosen were (1) all those of $5 \mathrm{lb} .8 \mathrm{oz}$. and under at birth, and (2) all those with birth weights of more than $5 \mathrm{lb} .8 \mathrm{oz}$. whose mothers would be able to attend with them at one of the three largest Infant Welfare Clinics in Sheffield, or one of the two largest clinics in Barnsley. The object of the survey was explained to all the mothers of these two groups and those cases were excluded in which either parent did not wish their child to take part.

\section{Method}

On each occasion the measurement taken was the maximum head circumference which, in view of the wide variations of head shape, was not constantly related to any fixed bony points. To obtain this measurement the baby was placed and held on one or other side and then the tape measure was placed round the widest part of the head, care being taken not to kink the tape or fix it in the wrong plane between the couch and the most dependent part of the baby's head. All measurements were taken to the nearest $0 \cdot 1$ of a centimetre with the tape unstretched but with all the slack taken up. At least three measurements were taken to ensure that the maximum circumference was being measured and the largest constant value was recorded, together with the body weight (unclothed) and the date, on a separate card for each infant. The measurement on each occasion was taken without reference to the previous one, and the result was written down immediately to avoid error. It became obvious very early in the survey that this strict routine had to be adhered to in order to avoid large errors. I took all measurements using a narrow linen tape which had been checked for accuracy before use against a centimetre scale. The tape was checked periodically against this standard and was discarded when it had stretched $0.5 \mathrm{~mm}$. per $10 \mathrm{~cm}$.

The first measurement was taken as soon after birth as possible, usually within the first 24 hours. A small minority was not measured until 2 days old. A second measurement was taken at 7 days old \pm 1 day, and a third at 2 weeks \pm 2 days, in those cases still in hospital. The vast majority of full-term infants, however, had been discharged from the Maternity Units before the third measurement could be taken. All the mothers, before discharge from hospital, were given an appointment to attend with the baby at the appropriate Welfare Clinic within seven to 13 days of going home. The aim was to obtain weekly measurements up to the age of 5 weeks and fortnightly measurements thereafter at $7,9,11,13$, 15 and 17 weeks of age, \pm half a week. This pattern was followed well in some cases, but in others, mainly through defaulting and partly due to the hiatus between the last measurement in hospital and the first clinic attendance, this timing was lost. In these cases, some of the measurements were taken on 'even weeks' of age. Finally, because so many fell into this group all measurements were related to the nearest week of age, and placed in weekly groups.

Those babies nursed in the Premature Baby Units had head circumference measurements taken in the same way as the full-term babies as soon after birth as possible and then at weekly intervals ( \pm one day) until discharged from the Unit. Because many of the babies were quite small and had a hospital stay of relatively long duration, regular weekly measurements presented no difficulties. After discharge from the Unit appointments were made to see the babies at the City General Hospital Premature Baby Clinic and in some cases at the local Infant Welfare Centre. From this time onwards the same difficulties of lack of regular clinic attendance were encountered as in the full-term babies. In the case of premature babies head measurements were taken at the clinics as frequently as possible (usually fortnightly) up to 26 weeks of age, and, as before, were finally divided into age groups of multiples of one week \pm half a week.

As expected, the attendance at clinics was variable; some mothers brought their babies regularly for the required length of time and others failed to attend at all. Between these extremes were those who came regularly but for short periods of time and others who attended sporadically. Table 1 shows these cases divided into groups according to the length of time of follow-up.

TABLE 1

NORMAL HEAD CIRCUMFERENCE SURVEY Time of Follow-up-All Cases

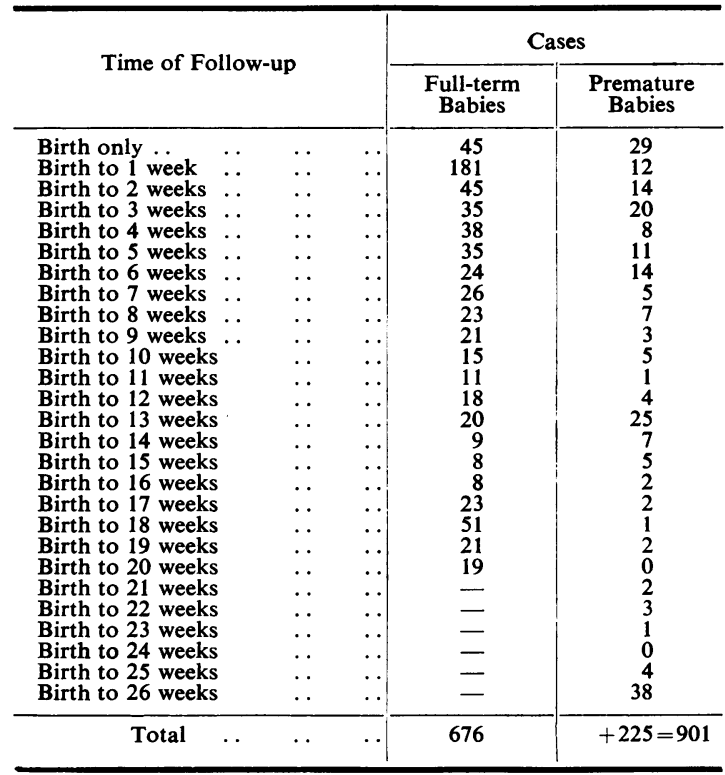

The survey of full-term infants lasted eight months and of premature infants 13 months. During that time 3,235 and 1,404 head circumference measurements were taken from the 676 and 225 full-term and premature babies respectively. In all, therefore, 901 male and female babies were involved in the survey and a total of 4,639 normal head circumference measurements was made. 
Results

The material collected in the above manner was presented to Dr. G. H. Jowett of the Department of Statistics, Sheffield University, and he and his assistant, Mrs. W. Wright, kindly analysed it. With the measurements went a request for the following items and charts:

1. A head circumference/age chart for full-term infants during the first three months of life.

2. A head circumference/age chart for premature babies during the first six months of life.

3. A chart to show the normal range of head circumference at birth related to birth weight, this chart to include both premature and full-term infants.

4. The normal range of increments of head circumference in premature and full-term infants, with special emphasis on details in the first weeks of life and with a view to the earliest possible diagnosis of deviations from the normal.

These will now be reported under their appropriate headings.

(1) Head Circumference/Age Chart for Full-term Infants. * This is reproduced in Fig. 1. It should be noted that in this and the other graphs of this report the boys' measurements have not been separated from those of the girls.

The curves were constructed by plotting the head circumference values from the record cards against age. From the scatter diagram so produced horizontal and vertical means were obtained; these were joined by eye and resulted in the mean curve. Histograms of deviations from the mean were constructed and from these the 2.5 and 97.5 percentiles were derived.

Unlike Westropp and Barber's (1956) and Falkner's (1958) results, those of the present series were detailed enough to demonstrate the relatively steep rise in head circumference found in the first six to eight weeks of life. From this time onwards the curves are very similar in all these charts, but those resulting from the present study show a narrower range, although they are comparable to those of Westropp and Barber (1956) and Falkner (1958) in that they represent $95 \%$ of the series. This difference probably lies in the fact that all the

* The actual values used for the construction of graphs described in this report can be obtained on application to the author. measurements of the present series were taken by one individual and that the values obtained were more closely related to the specified ages.

(2) Head Circumference/Age Chart for Premature Infants. The method of construction of this graph was exactly the same as for the full-term infants and the result is shown in Fig. 2. It should be noted that the curve representing the mean value is not centrally placed; this was presumably due to 'weighting' of the results with a larger proportion of big babies to small as would be expected in a survey of premature infants.

Fig. 3, which consists of the graphs of Figs. 1 and 2 superimposed, has been drawn to show the striking difference between the normal ranges of head circumference in full-term and premature babies. When seen in this way it is obvious how ridiculous it is to try and assess the head size of a premature infant by comparison with normal full-term standards.

(3) Chart to Show Normal Range of Head Circumference at Birth Relative to Birth Weight. Such a chart (Fig. 4) was constructed in a manner similar to the previous two, but in this case the head circumference values were plotted against birth weight and the curve was fitted to the means by 'least squares' instead of by eye. The graph covers a weight range from 3 to $9 \mathrm{lb}$. at birth. The curves are based on the maximum head circumference at 


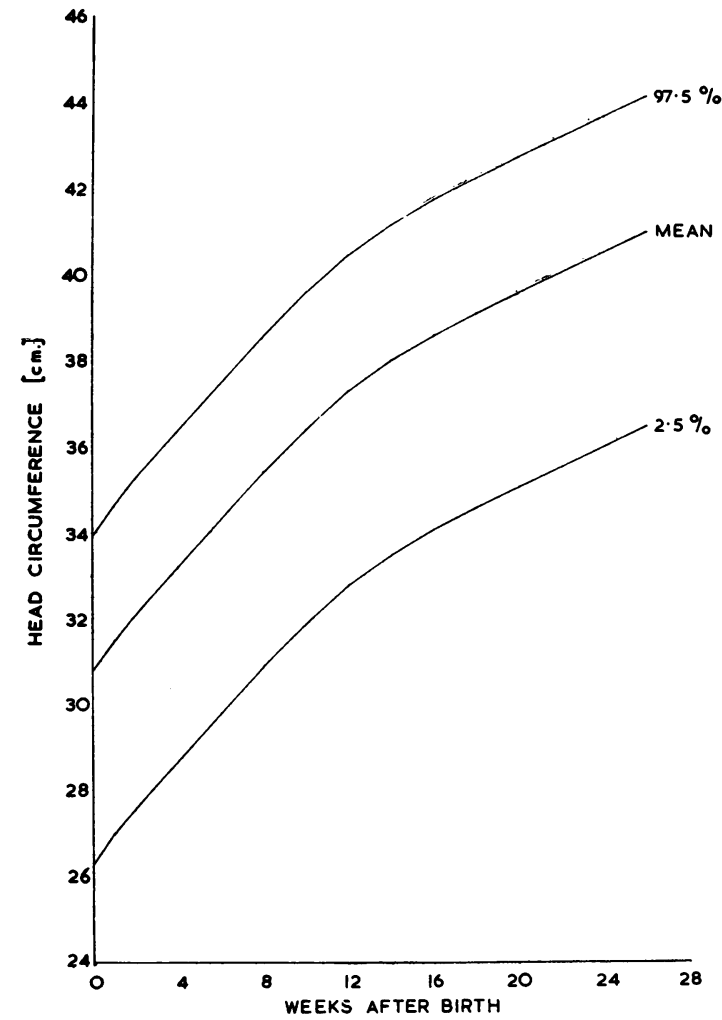

FIG. 2.-Head circumference/age chart for premature babies; $95 \%$ limits for head circumference with respect to age.

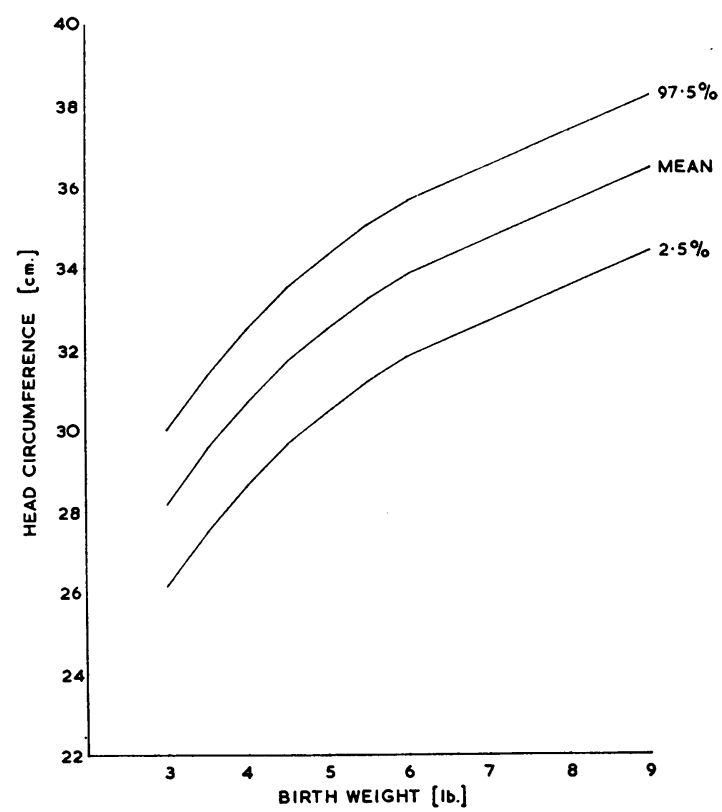

FIG. 4.-Head circumference relative to birth weight; $95 \%$ limits for head circumference at the first week relative to birth weight.

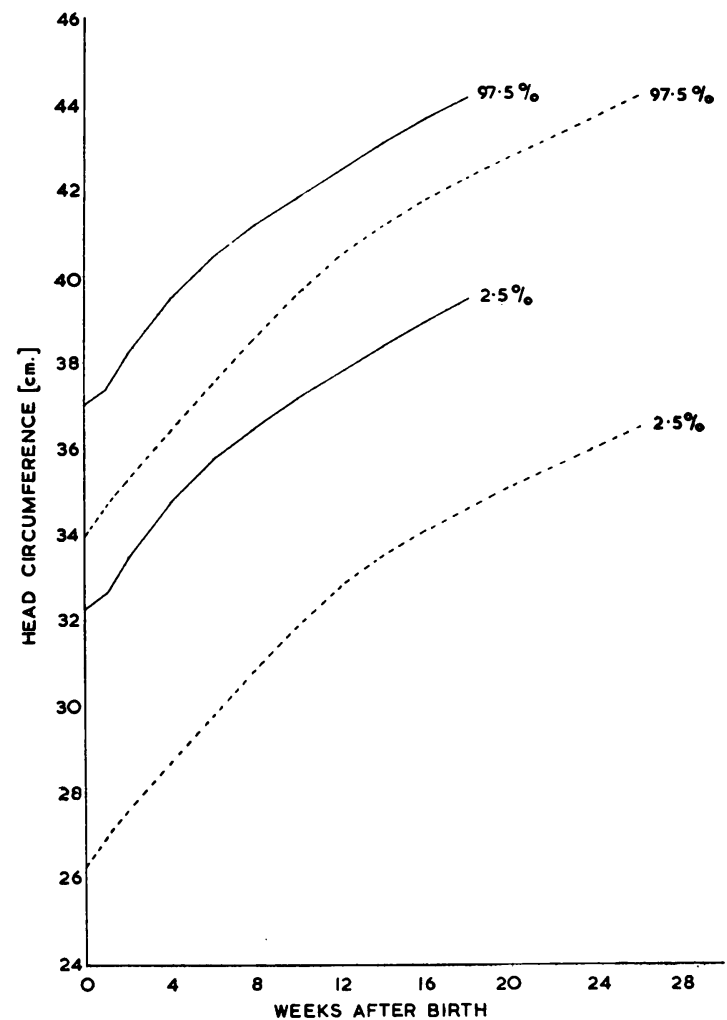

FIG. 3.-Graphs from Figs. 1 and 2 shown together for comparison; solid line: range of normal head circumference values for full-term infants; broken line: range of normal head circumference values for premature infants.

1 week of age, plus or minus one day, rather than on the measurements taken within the first two days of life. This is because moulding, caput formation and/or oedema of the scalp may result in gross changes in the head measurements in the first few days of life, so making those taken at 1 week the most reliable first measurement, which for all practical purposes can be regarded as the head circumference at birth. As with the previous charts, the range given covers $95 \%$ of normals.

(4) Normal Range of Increments of Head Circumference in Premature and Full-term Infants. The simplest method of diagnosing progressively abnormal head enlargement is by comparing increments of head growth with a normal range, and when the aim is the earliest possible diagnosis of advancing hydrocephalus these comparisons must be made no less frequently than at weekly intervals. As the rate of head growth is not constant the range of normal increments must be known for each week of age and at least two sets of figures, i.e. one for 
premature and one for full-term babies, should be available. Such charts would be useful but clumsy and, unfortunately, would involve the comparative use of small linear measurements so that the error would be relatively high. Also, any weekly increment of head increase could be judged as normal or abnormal but would show no relationship to previous values. To overcome these disadvantages, Dr. G. H. Jowett suggested that probably the best way to demonstrate deviations from the normal would be by the use of 'control lines' and a ratio chart. These will now be described in detail.

(a) Control Lines. To understand the significance of these lines it is necessary to know how they were constructed. For ease of description the age of 10 weeks will be taken as an example. The first step was to assume that all the normal head circumference measurements taken from the fullterm babies at the age of 10 weeks were superimposed upon a point $X$. This point (see Fig. 5) was made in a convenient position, unrelated to any fixed point on the ordinate but vertically above the 10week mark on the abscissa. The measurements on the same children, obtained between 10 weeks and birth, were then plotted backwards from point $\mathrm{X}$, using a 'sliding' logarithmic centimetre scale as the ordinate. (The reason for using a logarithmic scale will be explained under the next heading.) The points for each individual child were then joined and the result was a series of backwardly diverging lines, as shown in Fig. 5, the upper and lower limits of which represent the minimum and maximum rates of increase in head circumference in this group of normal infants. Any obviously stray line was disregarded when drawing the final boundaries separating normal from abnormal.

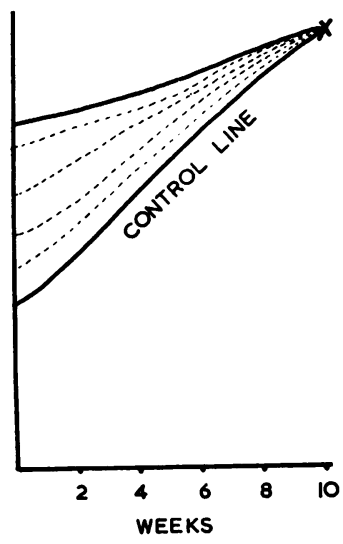

FIG. 5.-Diagram to demonstrate construction of contro lines. The two heavy lines diverging backwards from $X$ mark the limits of normal; the upper one represents the minimum rate of increase in head circumference and the lower one the maximum rate of increase in head circumference consistent with normality. In the present context the latter is known as the control line. In the diagram the control line for the 10th week is represented.

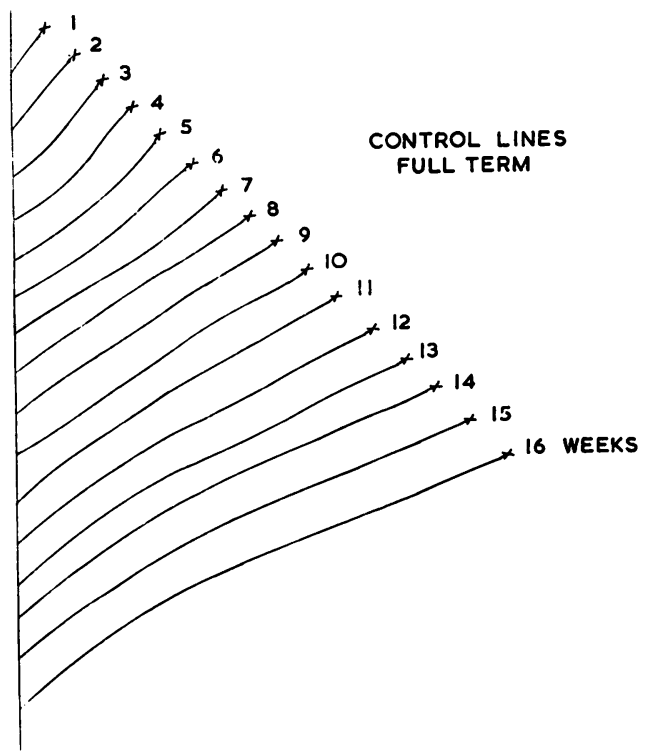

FIG. 6.-Control lines: full-term infants. Each line represents the maximum normal rate of increase in head circumference from birth to the week of age indicated by the number at the end of the line.

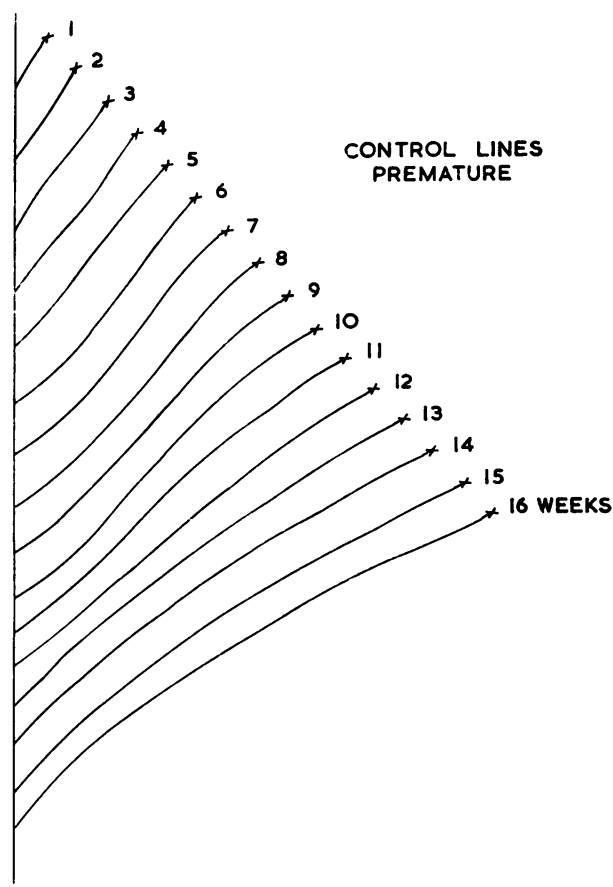

FIG. 7.-Control lines: premature infants. Each line represents the maximum normal rate of increase in head circumference from birth to the week of age indicated by the number at the end of the line. 
RATIO CHART FOR PLOTTING HEAD CIRCUMFERENCE

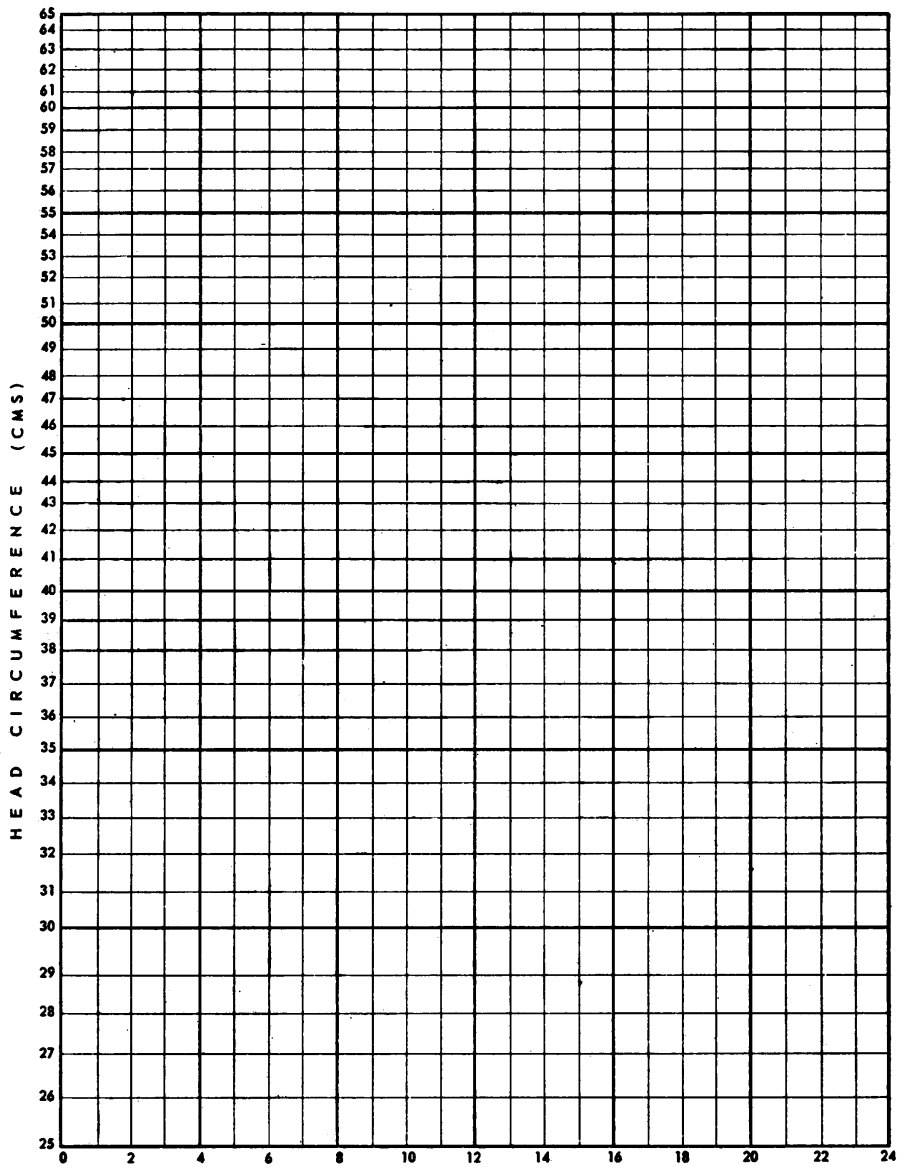

of control lines are shown in Figs. 6 and 7.

(b) Ratio Chart. The 'ratio chart' differs from the conventional head circumference/age chart in that the head circumference is plotted as a logarithmic scale in order to obtain, as far as possible, equal significance in the units of head growth of both large and small babies. A centimetre scale was chosen, and this, together with the age in weeks, was drawn on the same scale as the one on which the control lines were constructed. The result is shown in Fig. 8.

(c) USE OF RATIO ChaRT AND ConTrol Lines. To use these charts the head circumference, in centimetres, is first plotted against age on the ratio chart. The control lines are then superimposed on the latter, the ordinates of each graph being placed exactly one above the other as in Fig. 9. The transparency is then moved vertically up or down, still keeping the ordinates exactly matched, until the $X$ at the end of the control line of the appropriate week coincides with the patient's head circumference of the same week. If the head circumference growth curve lies below the control line, in part or in whole, then the rate of head growth has been abnormally rapid and, conversely, if it lies completely above the control FIG. 8.-Ratio chart for plotting head circumference.

Knowing this construction it is obvious that if any measurements taken from a head which is growing too rapidly are added to Fig. 5 (with the 10th week measurement coinciding with point $X$ ) the line produced will be steeper than any of the others and hence will lie below the normal range. It follows that the lowest of the normal lines represents the maximum rate of increase, or steepest gradient, consistent with normality, and it is this line, together with those for all other ages from 1 to 16 weeks, that constitute the 'control lines' previously referred to. This series and a similar one obtained from the premature baby measurements were drawn as two separate charts on transparent paper, the latter being necessary as the use of the control lines involves their superimposition upon a 'ratio chart' which will be described in the next paragraph. The two sets line the increments have been normal up to that age.

\section{PART II}

Method for Predicting Eventual Head Size in Early Stages of Infantile Hydrocephalus

The second part of this paper leads on naturally from the normal charts, just reported, to their use in the early stages of infantile hydrocephalus.

Either before or after birth there is a stage in the pathology of hydrocephalus in which the ventricles are expanding more rapidly than normal and a stage at which (no doubt through an equalization of pressures) the hydrocephalus arrests (Laurence, 1958). If operation to relieve intraventricular pressure is going to be of value then it clearly should be done during the progressive phase. To begin with, at least, it should not be performed in those patients in whom arrest is going to occur 
early and spontaneously in any case. It is therefore important to try and discover which cases will arrest early and which will arrest late.

Grouping. It is well known that in some children with manifest hydrocephalus the head circumference can still remain within normal limits: in others it can finish just above normal: in others it can become enormous. Arbitrarily, it was decided to call all those with normal head circumferences at the age of 1 year, Group 1: those with eventual head sizes no more than $5 \mathrm{~cm}$. above normal, Group 2 and those eventually above this, Group 3 (see Figs. 11, 12 and 13).

\section{Material}

The patients for analysis came from two sources. First there were 116 cases from two general paediatric and maternity units under the care of Drs. M. Eastwood and R. R. Gordon: these consisted of cases of 'pure' hydrocephalus, encephalocele and spina bifida cystica. Fifty-seven of these survived long enough to be put in a definite group. The remaining 42 patients were a similar series under the care of Mr. R. B. Zachary. There were therefore 99 cases available who could be placed in a definite group as previously defined.

The pathology of the 99 cases is shown in Table 2 with their eventual groups. Of the 47 cases who stayed in Group 1 there were several, of course, who had no signs of manifest hydrocephalus at all, but they have been included since any method of predicting head size should be capable of application to strictly normal heads as well as to grossly abnormal ones.

Most of the cases in the series who had spina bifida cystica had this 'repaired' in the first few days or weeks of life, but no operation for the relief of intracranial pressure was undertaken at any time on any patient and even fluid removed for investigations amounted to no more than a few millilitres.

\section{Method}

The objective was to be able to decide as early as possible into which group any individual child would eventually fall. By the use of the control lines and ratio chart described in Part I of this paper we can tell whether the head circumference is increasing more rapidly than normal but in most cases what we require is a method of telling whether this rapid rate of progression is going to continue.

Rate of increase alone is insufficient in predicting

TABLE 2

PATHOLOGY OF CASES USED FO R PREDICTING HEAD SIZE

\begin{tabular}{|c|c|c|c|c|}
\hline Pathology & Group 1 & Group 2 & Group 3 & Totals \\
\hline $\begin{array}{l}\text { Pure hydrocephalus } \\
\text { Encephalocele } \\
\text { Meningocele } \\
\text { Meningomyelocele . }\end{array}$ & $\begin{array}{r}3 \\
1 \\
29 \\
14\end{array}$ & $\begin{array}{r}2 \\
0 \\
5 \\
12\end{array}$ & $\begin{array}{r}11 \\
1 \\
1 \\
20\end{array}$ & $\begin{array}{r}16 \\
2 \\
35 \\
46\end{array}$ \\
\hline Totals & 47 & 19 & 33 & 99 \\
\hline
\end{tabular}

RATIO CHART FOR PLOTTING hEAD CIRCUMFEREMCE

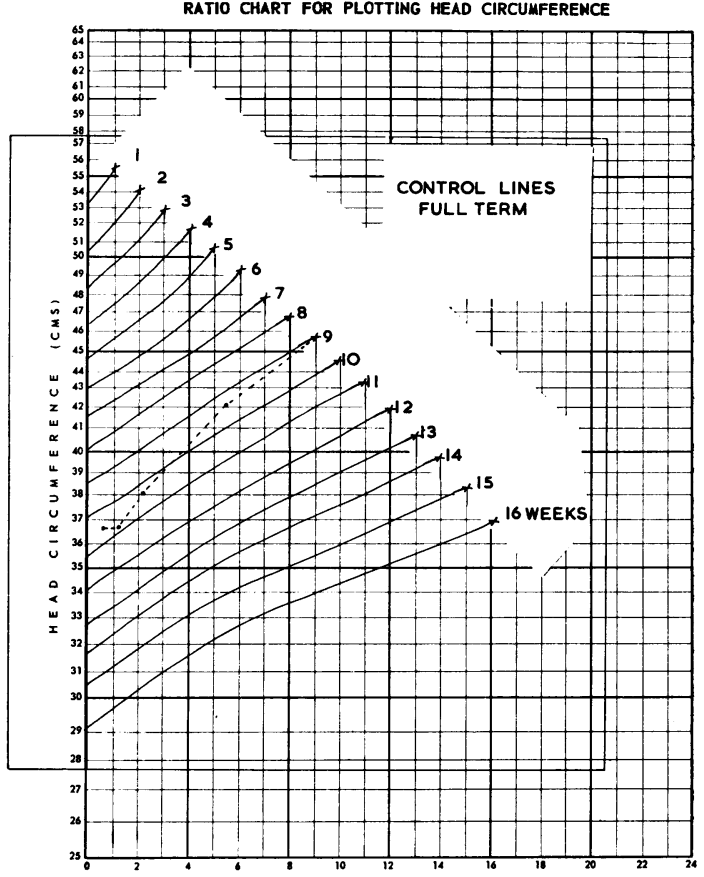

WEEKS OF AGE

FIG. 9.-Control lines superimposed on a ratio chart. . . . . . . . . line joining actual head circumference values. The control lines (for full-term infants) are placed in the position used to assess the rate of head growth at the age of 9 weeks, in a baby weighing $6 \mathrm{lb} .6 \mathrm{oz}$. at birth. The line joining the head circumference values lies below the 9-week control line and therefore head growth between birth and 9 weeks has been greater than normal.

eventual head size because in some cases of spina bifida cystica the actual head circumference at birth may be smaller than normal (Table 3 ) so that a considerable increase may not take the circumference out of the Group 1 range.

For this reason in the method to be described the starting point is taken as the actual head circumference at birth or the maximum head circumference for the birth weight ( 97.5 percentile), whichever is the greater, and this point is marked on the ordinate of the ratio chart at the beginning and is called the basic point. The infant's head is then measured once a week and the result is entered on the ratio chart. After recording

TABLE 3

ALL CASES OF SPINA BIFIDA CYSTICA WITH KNOWN HEAD CIRCUMFERENCE AT BIRTH AND KNOWN BIRTH WEIGHT

\begin{tabular}{|c|c|c|c|}
\hline \multicolumn{2}{|c|}{$\begin{array}{c}\text { Head Circumference Relative } \\
\text { to Birth Weight }\end{array}$} & No. of Cases & Percentage \\
\hline $\begin{array}{l}\text { Above } 97 \cdot 5 \text { percentile } \\
\text { Within normal range } \\
\text { Below } 2 \cdot 5 \text { percentile }\end{array}$ & $\begin{array}{l}\cdots \\
\cdots \\
\cdots\end{array}$ & $\begin{array}{l}11 \\
43 \\
12\end{array}$ & $\begin{array}{l}17 \\
65 \\
18\end{array}$ \\
\hline Totals & . & 66 & 100 \\
\hline
\end{tabular}


each weekly measurement the procedure is as follows:

1. Over the ratio chart place the appropriate control lines (full term or premature). The ordinates should match exactly.

2. Move the control lines vertically (keeping the ordinates matched) until the $X$ at the end of the appropriate weekly control line lies over the measurement for that week. It can then be seen if the rate of increase is too rapid.

3. Lay a ruler to join the 'basic point' on the ratio chart to the $\mathrm{X}$ of the control line of the week in question. This imaginary line is called the incremental line or line of increment.

4. If the line of increment each week lies above the control line then the head size will remain in Group 1.

If the line of increment comes to be at any one time completely below the control line then the head will finish in Group 3.

If the line of increment crosses a control line but at no time lies completely below one the eventual head size will be that of Group 2.

An example showing how Group 3 could be predicted at the age of 3 weeks is demonstrated in Fig. 10.

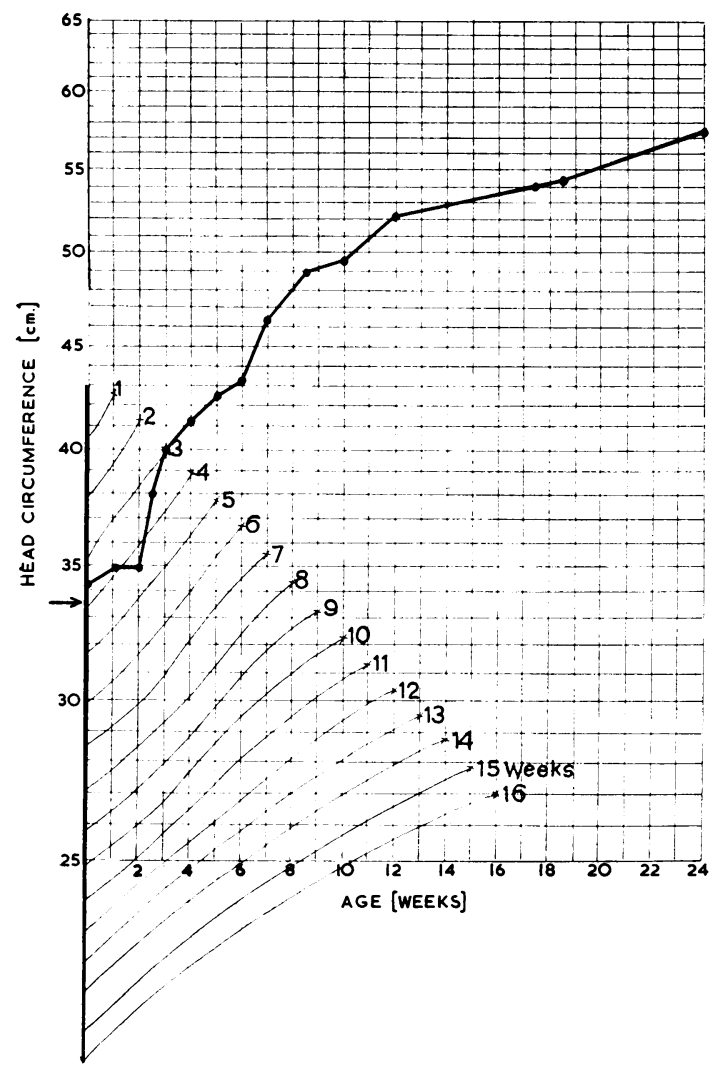

FIG. 10.

\section{Results}

Using the method just described in the 99 cases where the final head circumference at 1 year was known accurate predictions could have been made in $90 \%$ of them. The percentage accuracy of forecast of the three different groups is shown in Table 4 .

TABLE 4

INCIDENCE OF CORRECT PROGNOSIS OF GROUP

\begin{tabular}{|c|c|c|c|}
\hline & \multirow{2}{*}{ Cases } & \multicolumn{2}{|c|}{ Predicted Correctly } \\
\hline & & No. & $\%$ \\
\hline $\begin{array}{l}\text { Group } 1 \\
\text { Group } 2 \\
\text { Group } 3\end{array}$ & $\begin{array}{l}47 \\
19 \\
33\end{array}$ & $\begin{array}{l}46 \\
12 \\
31\end{array}$ & $\begin{array}{l}98 \\
63 \\
94\end{array}$ \\
\hline Totals & 99 & 89 & 90 \\
\hline
\end{tabular}

As expected, the least accurate group for prediction, when judged alone, is the middle one, but even so more than $60 \%$ could have been accurately diagnosed by this method and if one considers Groups 1 and 3 accuracy is as high as $98 \%$ and $94 \%$ respectively.

This has been a retrospective study but each case has been examined with a view to deciding what the outcome was likely to be and the prediction in each case has been checked against the actual result. By doing this it was found that using this new technique the group, indicating the eventual head size, could be diagnosed in the majority of cases well before the actual head size fell into that group, so that by using this method in future cases any surgery could be carried out well before gross enlargement had taken place. Table 5 shows the findings in the present series expressed in terms of weeks of warning in all cases in whom Groups 2 and 3 were predicted.

There were only 12 Group 2 cases to include in Table 5 and in only five of them was it possible to predict the final group before it was reached;

FIG. 10.-To demonstrate prediction of head size using control lines with a ratio chart. The control lines are numbered from 1 to 16 weeks and are drawn on transparent paper. In the above example they are placed in the position necessary to judge the future outcome for head size had the baby been considered at the age of 3 weeks. The ordinate of the control lines (heavy line) is superimposed on the ordinate of the ratio chart with the $\mathrm{X}$ of the control line for the third week coiniciding with the actual head circumference value for the same age. That part of the graph showing head growth from birth to 3 weeks lies below the third week control line so that head growth has exceeded the maximum normal rate during this period of time.

The incremental line is the imaginary line drawn from the basic point to (in this case) the third week measurement. Here it lies wholly below the third week control line so that Group 3 can be expected. This group was reached, in this example, at the age of 7 weeks.

Indicates the $97 \cdot 5$ percentile for head circumference relative to birth weight in this patient.

- - Actual head circumference values. 
TABLE 5

WARNING OF CHANGE OF GROUP

\begin{tabular}{|c|c|c|c|c|c|c|c|}
\hline \multirow{2}{*}{\multicolumn{2}{|c|}{ Final Group Reached }} & \multicolumn{5}{|c|}{ Weeks of Warning } & \multirow{2}{*}{$\begin{array}{l}\text { Total } \\
\text { Cases }\end{array}$} \\
\hline & & 0 & 1 & 2 & 3 & $\begin{array}{l}4 \text { or } \\
\text { More }\end{array}$ & \\
\hline $\begin{array}{l}\text { Group } 2 \\
\text { Group } 3\end{array}$ & $\begin{array}{l}. \\
\therefore\end{array}$ & $\begin{array}{l}7 * \\
0\end{array}$ & $\begin{array}{l}2 \\
4\end{array}$ & $\begin{array}{l}1 \\
2\end{array}$ & $\begin{array}{l}\mathbf{0} \\
\mathbf{2}\end{array}$ & 23 & $\begin{array}{l}12 \\
31\end{array}$ \\
\hline
\end{tabular}

* One of these was already in Group 2 at birth.

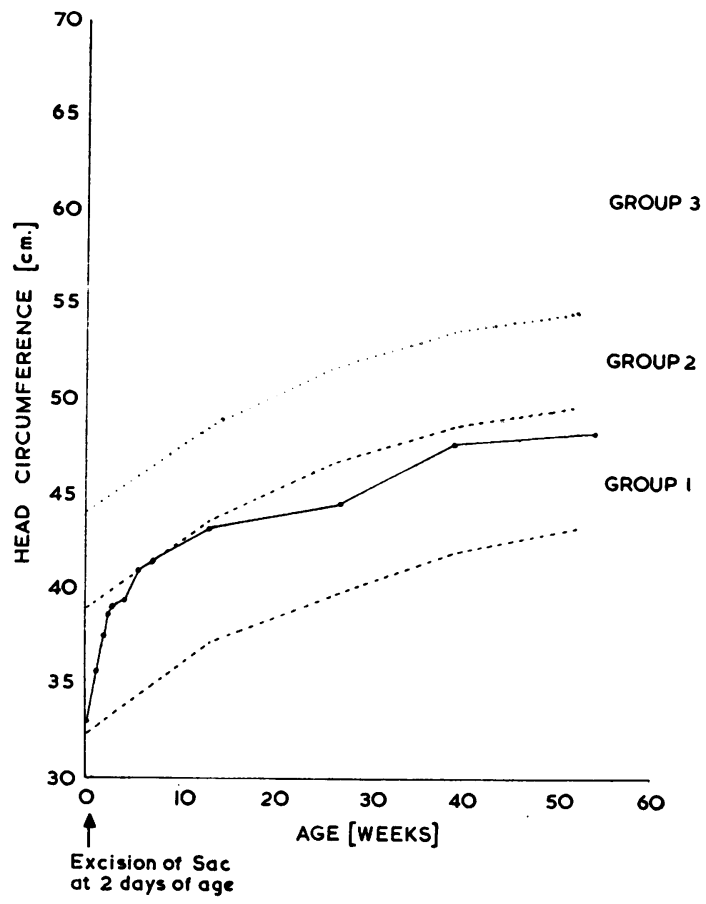

FiG. 11.

FIG. 11.-An example of Group 1 at 1 year of age; Case B.P.; Diagnosis: meningocele, clinical hydrocephalus; birth weight: $6 \mathrm{lb} .14 \frac{1}{2} \mathrm{oz}$.

Group 1 = Normal range of head size adapted from Westropp and Barber (1956).

FIG. 12.-Example of Group 2 at 1 year of age. Case L.S.; Diagnosis: meningomyelocele, clinical hydrocephalus; birth weight: $5 \mathrm{lb} .2 \mathrm{oz}$. Group 1 = Normal range of head size adapted from Westropp and Barber (1956).

FIG. 13.-Example of Group 3 at 1 year of age. Case J.I.; diagnosis: meningomyelocele, clinical hydrocephalus; birth weight $4 \mathrm{lb} .10 \mathrm{oz}$. Group 1 = Normal range of head size adapted from Westropp and Barber (1956).

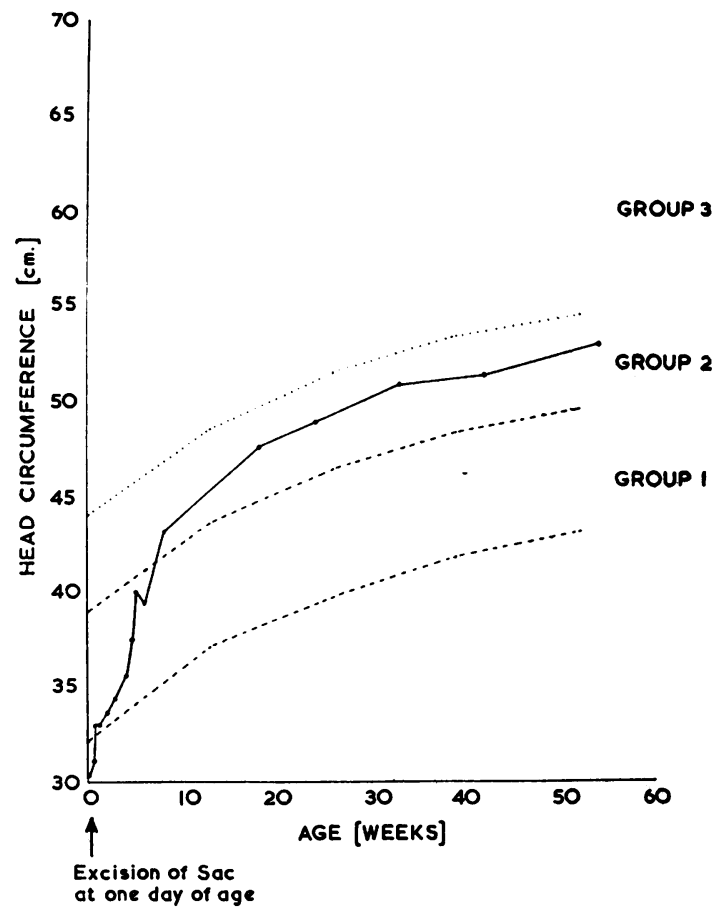

FIG. 12.

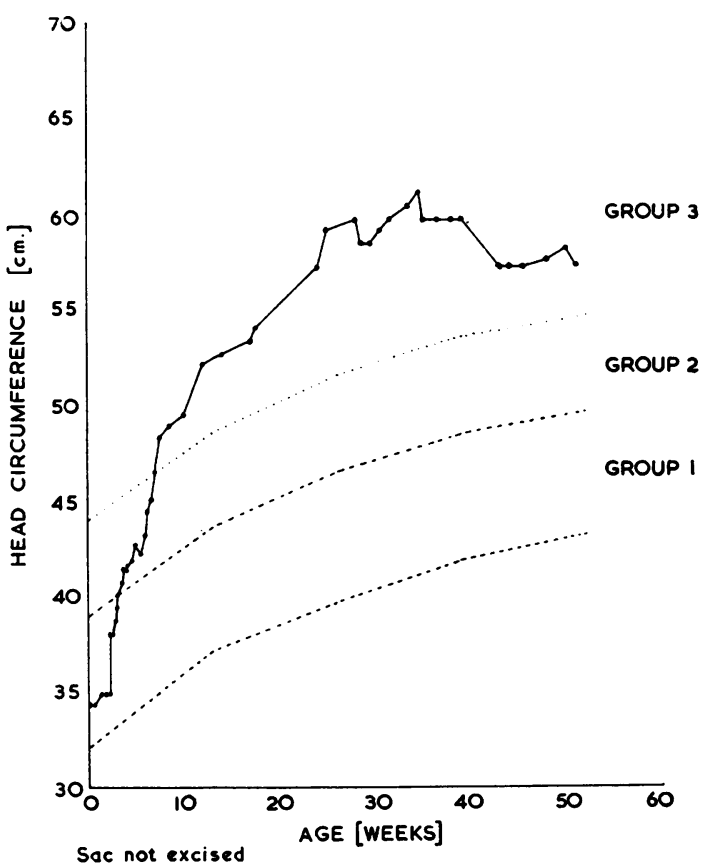

FIG. 13. 
the other six cases who showed a rise into Group 2 should not be disregarded because the control lines indicated in each of them that the head size would stay in Group 2, which it did. One case in which the head size was already in the latter group at birth is also included and in this child also the prediction was correct, the rate of increase of head size causing it to stay within the same group. The main interest, however, lies in those cases in Table 5 who eventually reached Group 3. In every single one of them there was at least one week's warning of entry into Group 3 and in 23 out of 31 cases $(74 \%)$ there were four or more weeks of warning of this happening.

Examples. Three examples are given to demonstrate the value of the new technique (Figs. 11, 12 and 13). It can be seen from their charts (which are ordinary head circumference/age charts amended for grouping purposes) that in all three cases there was a very rapid and comparable increase in head size initially, but eventually as arrest took place the final groups were 1,2 and 3. Only by the use of the control lines in the way described could the group in each case be accurately forecast during the stage of progression and in the Group 3 case this was forecast as early as the third week of life.

\section{DISCUSSION}

The survey of normal head growth was undertaken with the object of finding a method whereby the prognosis in the individual case of infantile hydrocephalus could be assessed. Strictly speaking, to detect progressive internal hydrocephalus increases of ventricular volume should be measured, but unfortunately there is no method of doing this which is simple and safe enough for frequent repetition. However, in most cases abnormal growth of the ventricles is reflected in external measurements of the skull and the most informative of these is the maximum head circumference. It was for this reason that the head circumference was chosen for the assessment of normal head size and growth.

\section{Normal Head Size}

Many charts are available showing the range of normal head size during the first year of life, but the vast majority of them are from cross-sectional data. It has been and still is common practice to take mean head circumference values from such charts at, say, birth and 12 weeks of age and by subtracting the difference and dividing by 12 calculating the average weekly rate of growth. Even as a rough guide such values can be very mis- leading. More accurate increments of growth can be obtained from the data of longitudinal studies, but those published so far have not been obtained with the diagnosis of any specific condition in mind and because of this the growth data have not been obtained at frequent enough intervals to reveal the changing growth rate in adequate enough detail. In normal children the greatest rate of change in head size occurs within the first few months of life and it is during this same period of time that the diagnostic and prognostic problems of infantile hydrocephalus arise. It was for this reason that the detailed normal head circumference/age chart for mature babies was only continued up to the age of 18 weeks, but even 16 weeks would have been adequate.

Head growth in premature babies has been neglected in the past. This is rather surprising because these babies have heads which, proportionately to the rest of the body, are larger than those of full-term infants so that the question of hydrocephalus is frequently raised. To eliminate this difficulty and also because the problem of hydrocephalus associated with spina bifida cystica is met in these babies too, the head circumference/age chart for premature babies was constructed from data as detailed as that for the mature infants. Values were obtained up to 26 weeks of age, but for the present purpose only those up to 16 weeks were needed.

Most textbooks quote values of chest circumference and/or crown-rump length as guides to head circumference relative to body size in infancy. The latter especially is difficult to measure with any degree of accuracy under ordinary clinical conditions and both can be very misleading. Although perhaps not the final answer to the problem it was felt that a chart showing the normal range of head size relative to body weight at birth would be useful. This, indeed, has proved to be so, this chart having become vital to the method of predicting head size described in this paper.

\section{Control Lines and Ratio Chart}

The control lines described in the first part of this report are graphical representations of rates of head growth and in no way indicate absolute measurements. Their sole function is to provide a boundary between the limits of normality and abnormality in the rates of increase of head circumference. Only the boundary indicating the maximum normal rate of head growth has been used in the present work. To record these values in numerical form complicated tables would have been needed in order to show a normal range of 
growth increments for babies with heads of different sizes. This difficulty was overcome in the present method by constructing separate sets of control lines for premature and full-term babies and by using a logarithmic scale for both the control lines and the ratio charts, so making the same percentage increases of head circumference of equal significance. The result is a very simple method of separating the rapid stage of normal head growth from the abnormal rate of growth seen in the early stage of infantile hydrocephalus.

\section{Basic Point and Incremental Line}

It has already been mentioned that in one child a very steep gradient of head growth may not necessarily take the head circumference beyond the normal limits of head size, and yet in another the same increment may result in a grossly enlarged head. This, quite obviously, is because of the great variability in head size at birth. Large heads at birth are expected in cases of hydrocephalus, but we have long suspected that some children with spina bifida cystica, who later have manifest hydrocephalus, had abnormally small heads at the start. Even so we were surprised to find that the ones with head circumferences below the 2.5 percentile amounted to almost $20 \%$ of the cases with spina bifida. In view of these findings it became obvious that rates of head growth could only be interpreted in terms of future head size, by standardizing the starting point from which increments of growth were to be measured. This resulted in the empirical development of the basic point, which has already been defined. In making a prediction of head size, growth is always considered as having taken place from this point so that the line of increment, which is drawn between the basic point and any later head circumference value, represents a standardized rate of growth. In using this method for forecasting, therefore, the curve drawn from the actual head circumference values is ignored and the line of increment only is compared with the control lines. By doing this all the previous difficulties were eliminated and the result was a method of making an individual prognosis for head size, in terms of the three defined groups. This was found to be accurate in $90 \%$ of the 99 cases upon whom it was tested.

\section{Fundamental Value of the Method}

Previously there has been no method of deciding which children with hydrocephalus will show early arrest and which will progress to the severe condition. Clearly, if any of these cases are to have corrective shunts the time to operate is in the pro- gressive phase and before the head has become abnormally large and brain compression severe. Admittedly, some of these children have normalsized heads together with gross cortical damage, but these cases are no longer in the progressive phase of hydrocephalus (which may have occurred in utero) so that a shunt would be of no use to them in any case. The real value of the method of prediction described here, therefore, is in its capacity to distinguish between what would eventually be mild, moderate and severe cases of hydrocephalus at a time when they cannot normally be distinguished, that is, when they are in the rapidly progressive phase. This is shown readily by the three examples given in Figs. 11, 12 and 13 where a child from each group (Groups 1, 2 and 3) is represented. Each of them showed a very rapidly progressive hydrocephalus, but by the new technique it was possible to anticipate the stage of arrest correctly and in the Group 3 case this prediction was made as early as the third week and whilst the head size was still normal. This quite obviously would have been the optimum time for surgery.

Much emphasis has been placed on the early prediction of eventual head size because this is so important if surgery is to aim at maintaining a normal or near normal head size with a minimum of brain damage. In the present series control lines up to the age of 16 weeks were quite adequate for this purpose, in fact, it was found that in $68 \%$ of those cases who finally reached Group 3 an accurate prediction of this group could have been given within the first eight weeks of life. It is possible that this may well be related to the fact that the vast majority of cases used for testing this method of prediction were patients with spina bifida cystica and that the patterns of head growth in these children are such that early prediction is possible in most cases. Nevertheless, this is of relatively little significance for in general paediatric practice the majority of cases of infantile hydrocephalus presenting within the first four months of life are associated with spina bifida cystica and hence the method is satisfactory for its requirements. But in any case the technique was also found suitable for forecasting head size in those cases of pure hydrocephalus presenting within the first 16 weeks. of life and included in the present series.

Although perhaps the method appears complicated, in fact the use of control lines is simple and easily learnt and only a few minutes is needed on each occasion for working out results. This is important because it means that the required information in each case can be obtained during the out-patient visit and in this way the parents 
can be given far more definite answers to their queries and, if surgery is indicated, arrangements for this and the preceding investigations can be made without delay. Such urgency should be appreciated because even one week's hesitation at a stage of very rapid abnormal head growth can result in gross hydrocephalus of the Group 3 grade.

As far as I am aware control lines have never been used before in the medical field. They were adapted for the present purpose by Dr. G. H. Jowett from the ideas of Page (1954) and Barnard (1959) who had previously drawn attention to them and emphasized their value for the inspection and control of industrial processes. Fortunately they are admirably suited to the present piece of work.

\section{SUMMARY}

1. A study of maximum head circumference measurements was made on normal full-term and premature babies. The survey was a longitudinal one and all measurements were taken personally. 676 full-term and 225 premature babies were involved and a total of 4,639 measurements was taken from these 901 infants. In the majority of cases head circumference values were obtained at birth and then at weekly and later fortnightly intervals up to 18 and 26 weeks of age from full-term and premature babies respectively.

2. From the material collected in the head circumference survey the following were obtained:

(i) A graph to show the normal range of head circumference in relation to age in full-term infants from birth to 18 weeks.

(ii) A head circumference/age chart to show the normal range of head size in premature babies from birth to 26 weeks of age.

(iii) A chart to show the normal range of head circumference at 1 week of age relative to birth weight. This covered a weight range of 3 to $9 \mathrm{lb}$. and therefore included premature as well as full-term infants.

(iv) Control lines. These were described with special emphasis on their significance and their use in association with a ratio chart. The 'lines' presented were drawn at weekly intervals from 1 to 16 weeks for both full-term and premature babies. Each control line represents a maximum normal rate of head circumference increase.
3. A method has been described for predicting the head size of any individual at 1 year of age in terms of defined groups. This technique resulted from an empirical modification of the use of control lines and depends on a knowledge of the maximum normal head circumference at birth relative to the birth weight. The predictions are made between birth and 16 weeks of age. The following results emerged from the application of this method to cases in the present series:

(i) An accurate forecast of the Group indicating head size was made in $90 \%$ of 99 cases.

(ii) Warning of the impending change of Group was given in just less than half of the Group 2 cases. In three-quarters of the Group 3 patients an accurate prediction of the final head size was made four or more weeks in advance of the change and in the remainder at least one week of warning was given in each case.

4. Three examples, forecast correctly to reach Groups 1, 2 and 3, were given. All three had a very rapidly progressive hydrocephalus, but it was possible during the progressive phase, to distinguish between early, moderately early and late arrest by the technique described in this report.

I wish to thank the Sheffield Regional Hospital Board for the opportunity to carry out this investigation; also Drs. R. R. Gordon, A. Kirk Black and G. A. W. Neill for allowing me to take measurements from children under their care, and Dr. R. R. Gordon, Mr. R. B. Zachary and Dr. M. Eastwood for access to their case notes. I am especially grateful to Dr. G. H. Jowett for the original idea of the control lines and to him and his assistant, Mrs. W. Wright, for constructing them and the head circumference charts from the material obtained during the survey. Finally, I would like to thank Dr. R. R. Gordon for the initial ideas which led to this survey and for his most valuable guidance throughout.

\section{REFERENCES}

Anderson, N. A. (1950). In Mitchell-Nelson Textbook of Pediatrics, 5th ed., p. 366 . Saunders, Philadelphia and London.

Barnard, G. A. (1959). Control charts and stochastic processes. $J$. R. statist. Soc., Series B (Methodological), 21, 239.

Crosse, V. M. (1957). The Premature Baby, 4th ed., p. 3. Churchill,

Falkner, F. (1958). Some physical measurements in the first three years of life. Arch. Dis. Childh., 33, 1.

Laurence, K. M. (1958). The natural history of hydrocephalus. Lancet, $2,1152$.

Low, A. (1952). Growth of Children. University Press, Aberdeen.

Myers, B. (1926). Statistics concerning the height, weight and other measurements of fourteen hundred London children. Brit. J. Child. Dis., 23, 87.

Page, E. S. (1954). Continuous inspection schemes. Biometrika,

Tanner, J. M. (1952). The assessment of growth and development in children. Arch. Dis. Childh., 27, 10.

Westropp, C. K. and Barber, C. R. (1956). Growth of the skull in young children. Part I: Standards of head circumference.
J. Neurol. Neurosurg. Psychiat., 19, 52. 